\title{
Direction-Of-Arrival Estimation for Adaptive Antenna Systems
}

\author{
Mrunal Patil ${ }^{1}$, D. G. Ganage ${ }^{2}$, M. B. Mali ${ }^{3}$ \\ ${ }^{I} P G$ Student, Dept. of E\&TC Engg, SCOE, Vadgaon (Bk.), Pune-41,India \\ ${ }^{2}$ Assistant Professor, Dept. of E\&TC Engg, SCOE, Vadgaon (Bk.), Pune-41,India \\ ${ }^{3}$ Professor and Head, Dept. of E\&TC Engg ,SCOE, Vadgaon (Bk.), Pune-41,India
}

\begin{abstract}
Adaptive smart antenna system manipulates the signal impinging on various antenna elements in such a way that, the main beam is directed towards the desired signal and a null is formed in the direction of interferers. Such smart antenna systems play a very important role in wireless and military applications as they can increase capacity, coverage range and resolution. To locate the desired signal, in smart antenna system direction of arrival (DOA) estimation algorithms MUSIC and ESPRIT are considered. This paper evaluates and compares MUSIC and ESPRIT DOA estimation algorithms which are mostly used in design of adaptive antenna system. MUSIC and ESPRIT provide a higher resolution and accuracy hence, are explored much in detail. Implementation of MUSIC and ESPRIT shows that, MUSIC is more stable and accurate than ESPRIT therefore, MUSIC is widely used to detect DOA of incoming signals.
\end{abstract}

Keywords: DOA, ESPRIT, MUSIC, Smart Antenna

\section{Introduction}

One of the most assured technique for increasing the capacity of cellular wireless communication and accuracy related to military applications is the adaptive array antenna. The smart antenna working basically deals with an array of antenna elements whose radiation pattern is controlled by adjusting the amplitude and phase of different antenna elements in the array. Signals impings on various antenna elements at the transmitter, whose time delay information is used by the adaptive smart antenna system to produce its output. Hence, this time delay must be appropriately combined at transmitter to be deciphered by the receiver. This information itself is used by the smart antennas to combine signals with greater fidelity or produce a null for the interfering signals and hence, improving the capacity for communication and accuracy for military purpose. The various DOA estimation algorithms are Bartlett, Capon, Min-norm, MUSIC and ESPRIT [3] [6] [8] [10]. But, MUSIC and ESPRIT algorithms are high resolution and accurate methods which has a huge response in the design of smart antennas and hence, their performance is evaluated in following sections.

\section{DOA Estimation Algorithms}

The purpose of DOA estimation is to get the direction of arrival of the incoming signals by using the estimate of data received by the array of antenna elements. As shown in Fig. 1, these results of DOA estimation are further used by the adaptive beam forming to locate the desired signal and produce a null for signals not of interest. Hence, the successful design of adaptive system block basically depends on, how well the DOA block estimates the incoming signals direction of arrival. The performance of DOA estimation algorithm depends on parameters like the number of antenna elements, their spacing, the number of signal samples and SNR. The DOA estimation algorithms have been evaluated and categorized into two methods viz. Conventional and subspace methods. Conventional methods also called as classical methods first compute a spatial spectrum and then estimate the DOA by local maxima of the spectrum[3] [4][6][8]. The methods that fall under this are the Bartlett, Capon methods but, these methods suffer from lack of angular resolution. Subspace based methods show a higher angular resolution and the methods that come under this is MUSIC and ESPRIT algorithms which are mostly used [1] [2] [5] [6] [9].

\section{MUSIC DOA Estimation Algorithm}

MUSIC is an acronym which stands for Multiple Signal Classification. It is high resolution technique based on exploiting the Eigen structure of input covariance matrix. MUSIC makes assumption that noise in each channel is uncorrelated making correlation matrix diagonal but, the incident signals are somewhat correlated creating non diagonal signal correlation matrix. Since, multiple signals direction of arrival (DOA) obtained at its output, this method of estimation is termed as the MUSIC method [2] [5] [8]. MUSIC method outputs a spectrum with certain peaks, present in the spectrum. The location of these peaks on $\mathrm{x}$ - axis is nothing but, the direction of arrival for each of the incoming signals. MUSIC requires Eigen values and vectors for its working. 


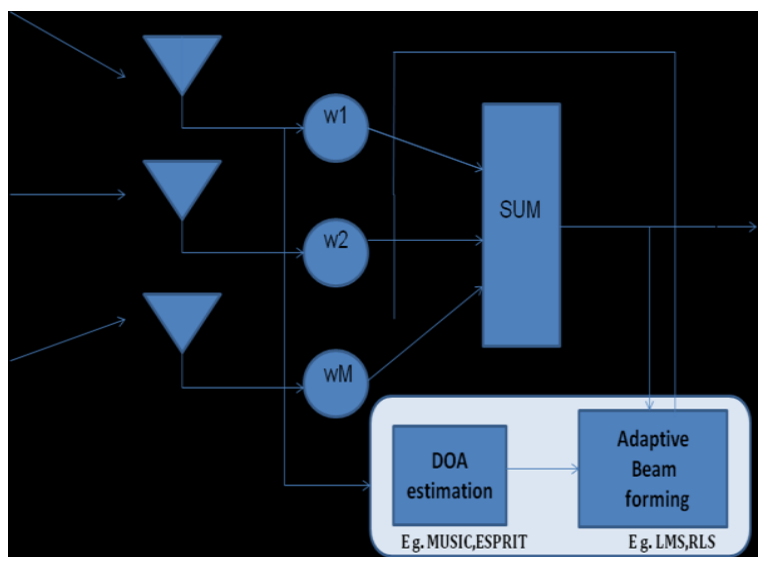

Fig.1 D Signals Impinging on M Antenna Elements

If the number of signals impinging on $\mathrm{M}$ element array is $\mathrm{D}$, the number of signal Eigen values and Eigen vector is $\mathrm{D}$ and the number of noise Eigen values and Eigen vectors is M-D then the Array Correlation Matrix with equal variances is given by,

$\mathrm{R}_{\mathrm{xx}}=\mathrm{A}^{*} \mathrm{Rss}^{\mathrm{H}} \mathrm{A}+\sigma \mathrm{n}^{2 *} \mathrm{I}$

Where, $A=\left[a\left(\theta_{1}\right) a\left(\theta_{2}\right)----a\left(\theta_{D}\right)\right]$ : Array Steering Matrix

$\mathrm{R}_{\mathrm{ss}}=\left[\mathrm{s}_{1}(\mathrm{k}) \mathrm{s}_{2}(\mathrm{k})\right.$----- $\left.\mathrm{s}_{\mathrm{D}}(\mathrm{k})\right]$ : Source Correlation Matrix

$R_{x x}$ has ' $D$ ' Eigen Vectors related to signals and M-D Eigen Vectors related with noise. So, we can construct the M-D subspace spanned by nose Eigen vectors such that,

$\mathrm{V}_{\mathrm{n}}=\left[\mathrm{V}_{1} \mathrm{~V}_{2^{-----}} \mathrm{V}_{\mathrm{M}-\mathrm{D}}\right]$

The noise subspace Eigen Vectors are orthogonal to array steering vectors at the angles of arrivals $\theta_{1}, \theta_{2}$----- $\theta_{\mathrm{D}}$ and the MUSIC power spectrum is given as,

$\mathrm{P}_{\mathrm{MUSIIC}(\theta)}=1 / \mathrm{abs}\left(\left(\mathrm{a}(\theta) \mathrm{V}_{\mathrm{n}} \mathrm{V}_{\mathrm{n}} \mathrm{a}(\theta)\right)\right.$

\section{ESPRIT DOA Estimation Algorithm}

ESPRIT stands for Estimation of Signal Parameters via Rotational Invariance Techniques which is another subspace based DOA estimation algorithm. It does not involve an exhaustive search through all possible steering vectors to estimate DOA and hence, reduces the computational and storage requirements as compared to MUSIC. ESPRIT scans two arrays called doublets at a time in a translational way. ESPRIT assumes $\mathrm{D}<\mathrm{M}$ sources centered at frequency fo. Fig. 2 shows four element linear array composed of two doublets [3] [4] [6] [8].

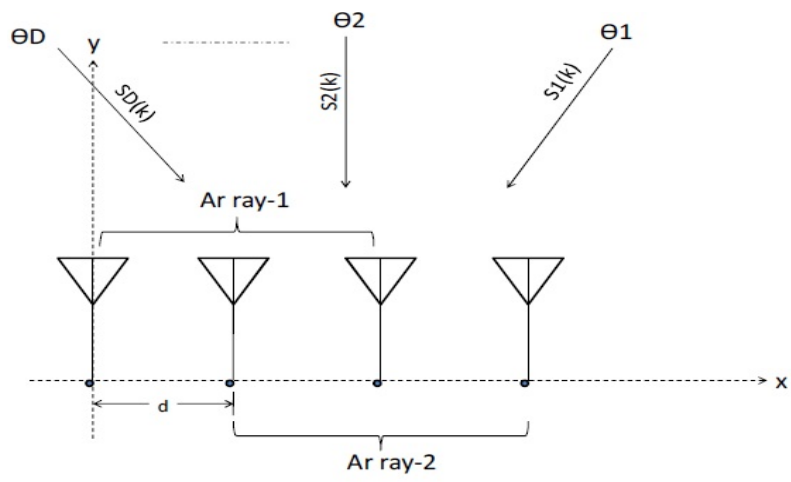

Fig. 2 Four element linear array with two doublets

The two sub arrays, Array-1 and Array- 2 are displaced by distance 'd'. The signals induced on each of the arrays are given by,

$\mathrm{x}_{1}(\mathrm{k})=\mathrm{A}^{*} \mathrm{~s}(\mathrm{k})+\mathrm{n}_{1}(\mathrm{k})$ 


$$
\begin{aligned}
& \mathrm{x}_{2}(\mathrm{k})=\mathrm{A} * \Lambda^{*} \mathrm{~s}(\mathrm{k})+\mathrm{n}_{2}(\mathrm{k}) \\
& \mathrm{jkd} \sin (\theta 1) \quad \mathrm{jkd} \sin (\theta 2) \quad \mathrm{jkd} \sin (\theta 3) \\
& \text { where, } \begin{aligned}
\Lambda= & \operatorname{diag}\{\mathrm{e} \quad \mathrm{e}--------\mathrm{e} \\
= & \operatorname{diagonal} \text { unitary matrix with phase shifts } \\
& \text { between doublets for each DOA }
\end{aligned}
\end{aligned}
$$

Creating a signal subspace for the two sub arrays results in two matrices $\mathrm{V}_{1} \& \mathrm{~V}_{2}$. Since, the arrays are translationally related, the subspaces of Eigen vectors are related by a unique non-singular transformation matrix $\varphi$ such that,

$\mathrm{V}_{1} \varphi=\mathrm{V}_{2}$

There must also exist a unique non-singular transformation matrix $\mathrm{T}$ such that, $\mathrm{V}_{1}=\mathrm{AT}$ and $\mathrm{V}_{2}=\mathrm{A} \Lambda \mathrm{T}$

and finally we can derive, $\mathrm{T} \varphi \mathrm{T}^{-1}=\Lambda$

Thus, the Eigen values of $\varphi$ must be equal to the diagonal elements of $\Lambda$ such that,

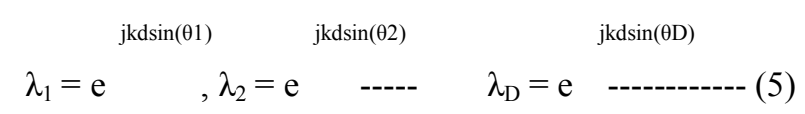

Once, the Eigen values of $\varphi, \lambda_{1}, \lambda_{2}$----- $\lambda_{\mathrm{D}}$ are calculated, we can estimate the angles of arrival as,

$$
\theta_{\mathrm{i}}=\sin (\arg (\lambda \mathrm{i}) / \mathrm{kd})
$$

From above equations it becomes clear that, ESPRIT eliminates the search procedure and produces the DOA estimation directly in terms of Eigen values without much computational and storage requirements. This Eigen structure shows excellent accuracy and resolution in many applications [3] [4] [7] [10].

\section{Results And Discussions}

The simulation results are obtained for MUSIC and ESPRIT method of DOA Estimation by varying the number of antenna elements $(\mathrm{N})$, number of signal sources $(\mathrm{K})$, angles of arrival (AOA) and signal to noise ratio for incoming signals in MatlabR2008a software. Results for MUSIC Fig.3 shows, the graph for angle of arrival (x-axis) Vs directional spectrum (y-axis) for $\mathrm{N}=10$ and $\mathrm{K}=4$; Fig.4 depicts graph for $\mathrm{N}=20$ and $\mathrm{K}=4$. Similarly, Fig. 5 and 6 show graphs for $\mathrm{K}=3, \mathrm{~N}=20$ and $\mathrm{K}=5, \mathrm{~N}=20$ respectively. Fig. 7 and 8 accurately detects angles of arrival for $10^{\circ}, 30^{\circ}, 50^{\circ}, 70^{\circ}, 90^{\circ}, 100^{\circ}, 120^{\circ}, 150^{\circ}, 240^{\circ}, 360^{\circ}$ respectively.Results obtained for ESPRIT fig. 9 and fig. 10 depicts the graph for varying the number of antenna elements $(\mathrm{N})$ on $\mathrm{x}$-axis from 2 to 3 Vs AOA on yaxis; Fig. 11, 12 shows graph for varying the signal to noise from 10 to 20 respectively and Fig. 13 refers to graph that detects all the incoming signals in an accurate manner.

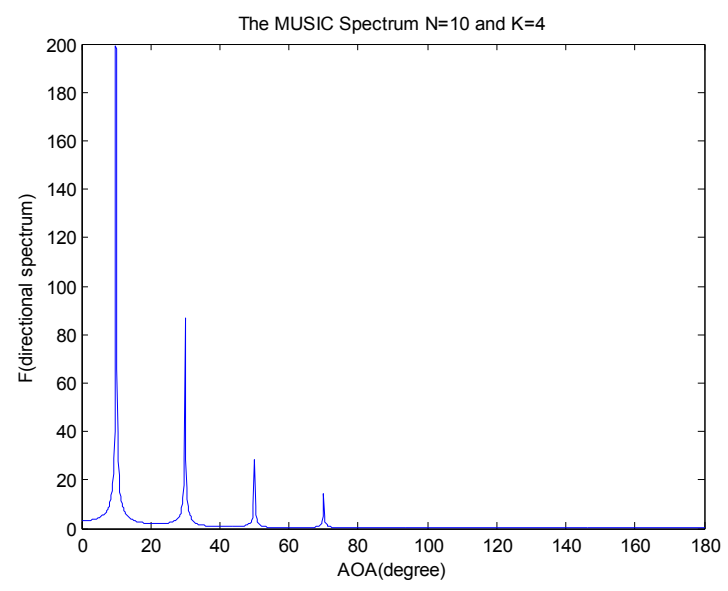

Fig. 3: Effect of varying number of antenna elements $(\mathrm{N}=10)$

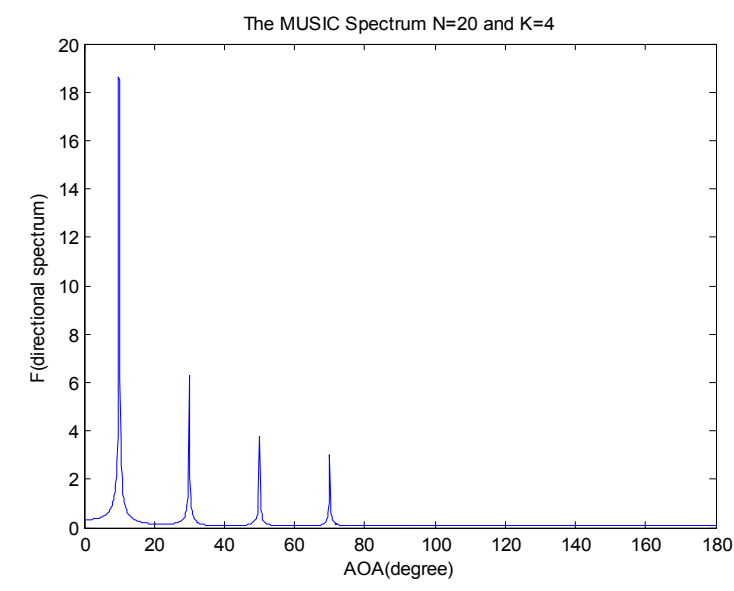

Fig. 4: Varying the number of antenna elements $(\mathrm{N}=20)$ 


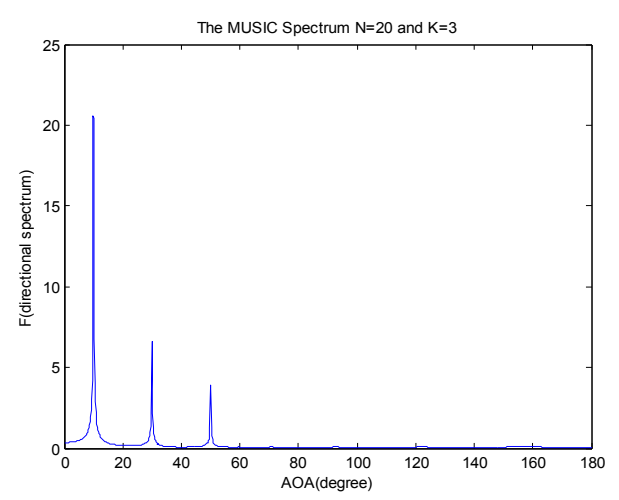

Fig. 5: Effect of varying number of incoming signals $(\mathrm{K}=3)$

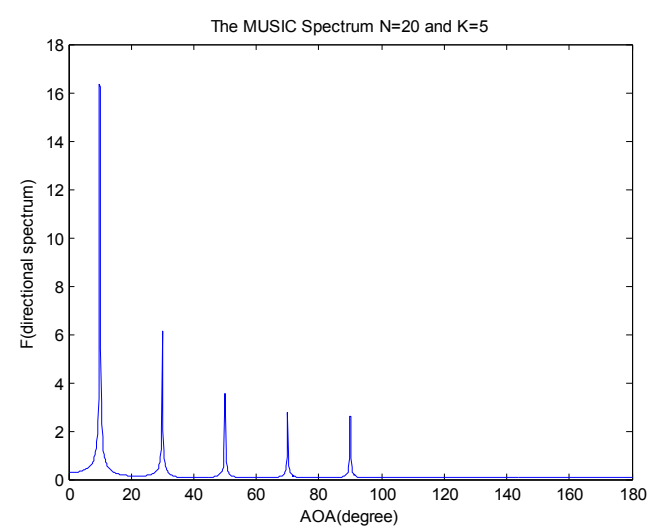

Fig. 6 :Varying the number of incoming signals $(\mathrm{K}=5)$

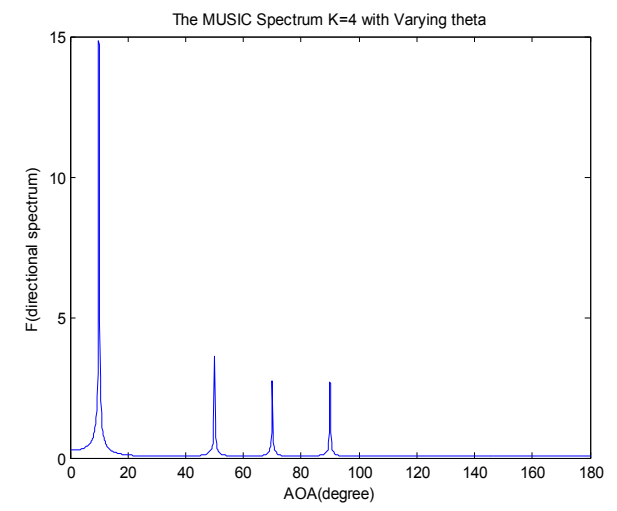

Fig.7: Detection of Incoming signals at $10^{\circ}, 50^{\circ}$, $70^{\circ}, 90^{\circ}, 120^{\circ}$

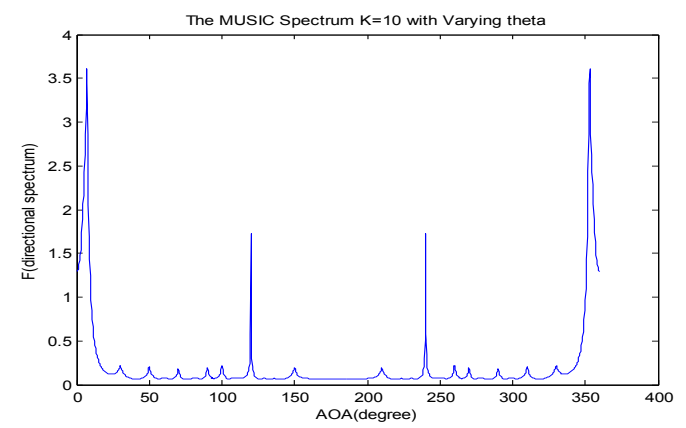

Fig. 8: Detection of incoming signals at $10,30,50,70,90,120,240,360^{\circ}$

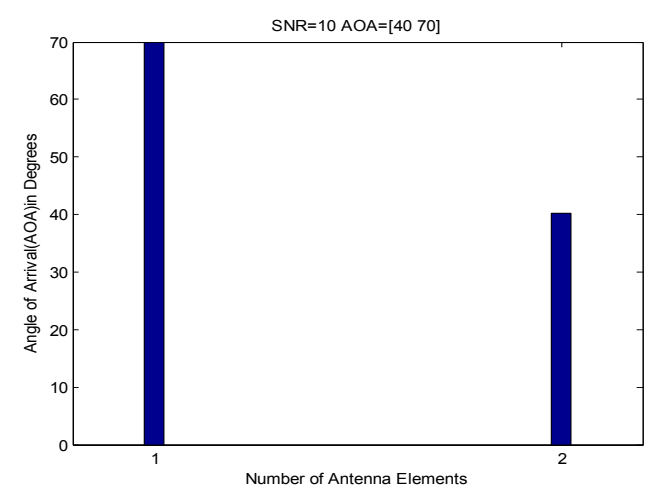

Fig.9: Varying the number of antenna elements $(\mathrm{N}=2)$

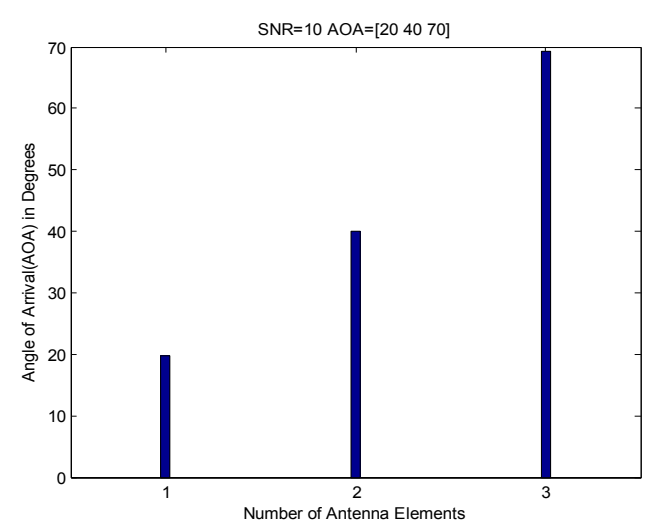

Fig.10: Varying the number of antenna elements $(\mathrm{N}=3)$

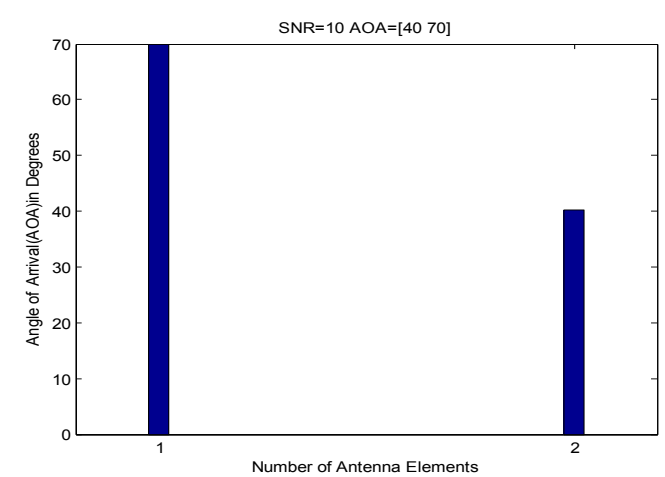

Fig.11: Varying the signal-to-noise ratio $(\mathrm{SNR}=10)$ 


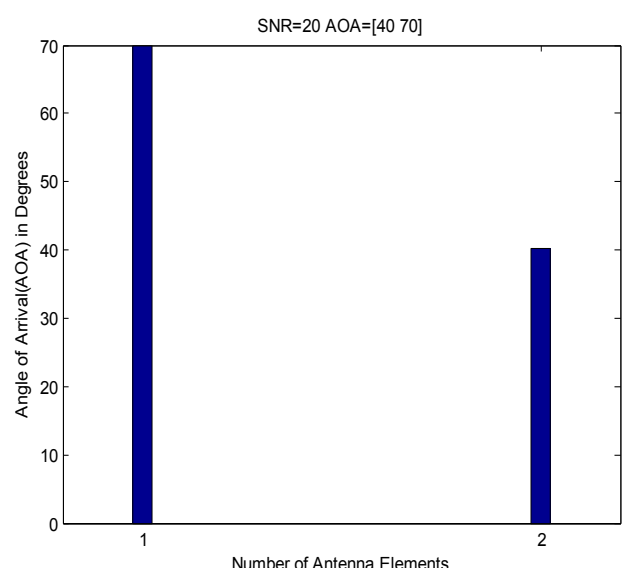

Fig.12: Varying the signal-to-noise ratio $(\mathrm{SNR}=20)$

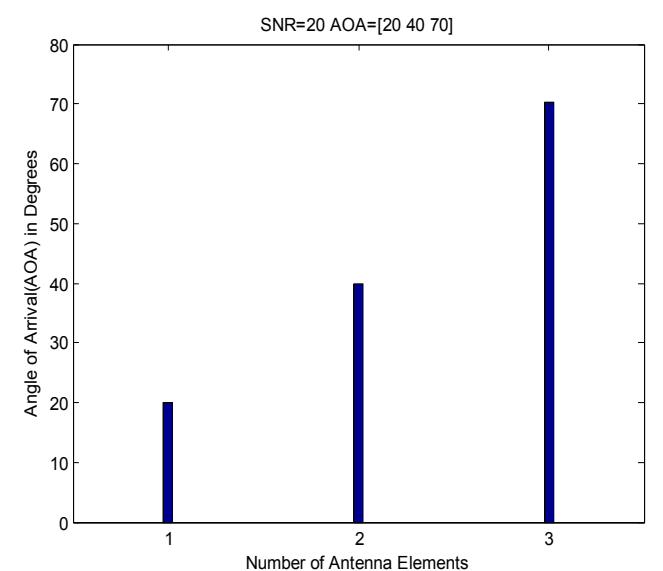

Fig.13: Detection of incoming signals at $20^{\circ}, 40^{\circ}, 70^{\circ}$

\section{Conclusions}

This paper presents the simulation results for MUSIC and ESPRIT method of DOA Estimation. Since, MUSIC and ESPRIT methods have greater resolution and accuracy hence, are evaluated in detail. Table 1 shows performance of MUSIC that improves as the number of elements in the array and for greater angular separation between the signals. These improvements are seen in the form of sharper peaks in MUSIC spectrum. Table 2 shows the performance of ESPRIT algorithm which improves when SNR and number of antenna elements are increased. These improvements are seen in form of smaller angle detection for ESPRIT DOA Estimation technique.

Table 1: Simulation Results for MUSIC Algorithm

\begin{tabular}{|c|c|c|}
\hline $\begin{array}{l}\text { Varying Parameters } \\
\text { (DOA Estimation) }\end{array}$ & $\begin{array}{c}\text { Observed } \\
\text { Output }\end{array}$ & Conditions \\
\hline $\begin{array}{l}\text { [a] Number of } \\
\text { antenna elements } \\
\text { (N) increased } \\
\text { from } 10 \text { to } 20\end{array}$ & $\begin{array}{l}\text { - Peaks of } \\
\text { spectrum } \\
\text { become } \\
\text { sharper }\end{array}$ & $\begin{array}{l}\text { (a) Output } \\
\text { observed } \\
\quad \text { for } \\
\mathrm{AOA}=\left(10^{\circ}, 30^{\circ}, 50^{\circ} \text {, }\right. \\
\left.90^{\circ}, 120^{\circ}\right) \\
\text { (b) } \mathrm{K}=4 \\
\text { (c) Spacing } \\
\text { between } \\
\quad \text { elements is } 0.5\end{array}$ \\
\hline $\begin{array}{l}\text { [b] Number of } \\
\text { snapshots }(p) \\
\text { increased }\end{array}$ & $\begin{array}{l}\text { - Precise } \\
\text { detection } \\
\text { of incoming } \\
\text { signals } \\
\text { - Resolution } \\
\text { capacity } \\
\text { increases }\end{array}$ & $\begin{array}{l}\text { (a) } \mathrm{K}=4 \\
\text { (b) } \mathrm{N}=20\end{array}$ \\
\hline $\begin{array}{l}\text { [c] AOA } \\
\text { Detection }\end{array}$ & $\begin{array}{l}\text { - Incoming } \\
\text { signals very } \\
\text { accurately } \\
\text { detected using } \\
\text { MUSIC DOA } \\
\text { Estimation } \\
\text { process }\end{array}$ & $\begin{array}{l}\text { (a) Values } \\
\text { considered: } \\
(10,30,50,70,90,12 \\
\left.0,150,240,360^{\circ}\right) \\
\text { (b) } \mathrm{K}=4,10 \\
\text { (c) } \mathrm{N}=20\end{array}$ \\
\hline
\end{tabular}


Table 2: Simulation Results for ESPRIT Algorithm

\begin{tabular}{|c|c|c|}
\hline $\begin{array}{l}\text { Varying Parameters } \\
\text { (DOA Estimation) }\end{array}$ & $\begin{array}{c}\text { Observed } \\
\text { Output }\end{array}$ & Conditions \\
\hline $\begin{array}{l}\text { [a] Number of } \\
\text { antenna elements } \\
\text { (N) increased } \\
\text { from } 2 \text { to } 3\end{array}$ & $\begin{array}{l}\text {-More precise } \\
\text { detection of } \\
\text { incoming signal } \\
\text { angle }\end{array}$ & $\begin{array}{l}\text { (a) Output observed for } \\
\mathrm{AOA}=\left(20^{\circ}, 40^{\circ}, 70^{\circ}\right) \\
\text { (b) } \mathrm{K}=2,3 \\
\text { (c) } \mathrm{SNR}=10\end{array}$ \\
\hline $\begin{array}{l}\text { [b] SNR increased } \\
\text { from } 10 \text { to } 20\end{array}$ & $\begin{array}{l}\text {-Less errors in } \\
\text { angle detection } \\
\text { at output }\end{array}$ & $\begin{array}{l}\text { (a) Output observed for } \\
A O A=\left(40^{\circ}, 70^{\circ}\right) \\
\text { (b) } \mathrm{N}=2\end{array}$ \\
\hline $\begin{array}{l}\text { [c] AOA } \\
\text { Detection }\end{array}$ & $\begin{array}{l}\text {-All incoming } \\
\text { signals very } \\
\text { accurately } \\
\text { detected using } \\
\text { ESPRIT DOA } \\
\text { Estimation } \\
\text { Process }\end{array}$ & $\begin{array}{l}\text { (a) Values considered: } \\
\left(20^{\circ}, 40^{\circ}, 70^{\circ}\right) \\
\text { (b) } \mathrm{K}=3 \\
\text { (c) } \mathrm{N}=20\end{array}$ \\
\hline
\end{tabular}

\section{References}

[1]. Reaz, K. Haque, F. Matin, " A Comprehensive Analysis and Performance Evaluation of different Direction Of Arrival Estimation Algorithms“, IEEE Symposium on Computers \& Informatics (ISCI), 2012, vol 18-20, March 2012, pp 256, 259

[2]. M. P. Priyadarshini and R. Vinutha, " Comparative Performance Analysis of Music and ESPRIT on ULA", International Conference on Radar, Communication and Computing (ICRCC), vol 21-22, Dec. 2012, Pages 120 $-124$

[3]. Oumar, Ousmane Abdoulaye, Siyau, Ming Fei, Tariq P., "Comparison between MUSIC and ESPRIT Direction of Arrival Estimation Algorithms for Wireless Communication Systems, " Future Generation Communication Technology (FGCT), Vol 12, 13 , Dec 2012, Pages 99-103

[4]. Lavate, T. B. Kokate, V. K. Sapkal, A. M., " Performance Analysis of MUSIC and ESPRIT DOA Estimation Algorithms for Adaptive Array Smart Antenna in Mobile Communication, Second International Conference on, " Computer and Network Technology (ICCNT), 2010, vol 23-25, April. 2010, pp.308, 311

[5]. J. C. Liberti, T. S. Rappaport. "Smart antenna for wireless communications," India, 1999

[6]. Moustafa M. Abdallah, Mostafa B. Abuitbel, Mohamed A. Hassan, “ Performance Evaluation of Direction of Arrival Estimation Using MUSIC and ESPRIT Algorithms for Mobile Communication Systems", as part of the main Technical program at IFIP WMNC' 2013.

[7]. Ayman Abdallah, Soubhi Abou Chabin, Mouhammed Ramm Guillaumme, Patr Vaudont, Michel Campo Vecchiol, "A Smart Antenna Simulation for (DOA) Estimation Using MUSIC and ESPRIT Algorithms", 23rd National Radio Science Conference, March - 2006.

[8]. D. Spiel man, A. Paulraj, and T. Kailath,“ Performance Analysis of the MUSIC Algorithm," in Proceedings IEEE International Conference Acoustic and Speech Signal Processing, Vol.11, Apr.19.

[9]. Richard Roy and Thomas Kailath, " ESPRIT-Estimation of Signal Parameters Via Rotational Invariance Techniques" , Transaction on acoustics, speech and signal processing, vol no 37, July,1989.

[10]. R. Roy, A. Paulraj and T. Kailath, "Estimation of Signal Parameter via Rotational Invariance Techniques-ESPRIT", IEEE Trans. on ASSP, ASSP- 34 (4), August 1986, pages : 41.6.1- 41.6.5

[11]. Xinying Li, Guiqin Yang, Yaoke Gu " Simulation Analysis of MUSIC Algorithm of Array Signal Processing DOA ", IEEE Transations on Signal Processing, March 2008, pages : 598-614. 